\title{
NATIONAL POLICY AND THE COMMUNITY DEVELOPMENT CORPORATION
}

\author{
Stewart E. Perry*
}

As the community development corporation (CDC) becomes more familiar to those concerned with public law and policy relating to inner city problems, there is a tendency to consider CDC's merely as part of some federal program and therefore relevant to federal or national policy primarily on that ground. An OEO program does in fact support about forty CDC's, and other CDC's are organized under HUD's Model Cities programs. Yet the CDC is much more than a federal program vehicle. It is in fact the expression of a socio-political movement and process that is much broader than the urban renewal and poverty programs.

Although the main goal of the CDC is inner-city or rural economic development, it is actually a multi-purpose social institution and can take different forms. ${ }^{1}$ This results from the fact that CDC's originally emerged spontaneously in widely separated cities and rural areas and were not the product of a governmentally prescribed pattern. In fact, federal officials and others have specifically turned to CDC's because as a preexisting organizational form, they are presumably more effective and credible in low-income areas. ${ }^{2}$ The form itself, however, is not as significant as the nascent social developments that it represents. From these social developments come its significance for national policy.

This article will describe briefly the more recent historical background of the CDC movement, try to suggest the similarity of the CDC movement to a similar middle-class concern, link these to general policy problems of decentralization and rural development, and, finally, discuss some specific, though minor, restrictions in federal policy that prevent full utilization of the energy that the CDC expresses.

The immediate historical background of the CDC both as an idea and as an institution offers a clue to social trends in our country. The problems associated with these trends have been conceptualized in the bureaucracies and agencies of

- Director, Center for Community Economic Development, Cambridge, Massachusetts. I owe a debt to Jeff Faux and Helen Perry for their colleagueship on this article.

${ }^{1}$ For descriptions of a wide variety of CDC's, see a joint publication of the Center for Community Economic Development and the Cambridge Institute, Profiles in Community-Based Economic DevelopMENT (197I). Only urban CDC's are included in this pamphlet, which describes 27 groups.

2 This history appears in a paper by the author prepared for the Society for Applied Anthropology in 1968, to be published under the title Black Separatism, Black Institutions, and Economic Development in Human Organization. Essential reading is a book just published by the Twentieth Century Fund Task Force on Community Development Corporations: CDC's: NEw Hope FOR THE INNER CITY (I97I). The conceptual framework for the CDC was a collaborative effort at Harvard's Kennedy Institute by Gar Alperovitz, John McClaughry, and Roy Innis. One of the earliest published treatments of the CDC concept is in Socias InNovation IN THE CITY (R. Rosenbloom \& R. Marris, eds. I969). I have drawn from my own earlier paper, $A$ Note on the Genesis of the Community Development Corporation, in Case for Participatory Democracy (G. Benello \& D. Roussopoulos, eds. I97I). 
Washington for federal programs. Yet the connection between what is happening in city neighborhoods and rural communities in the evolution of the CDC and what must be dealt with on a national level has not yet been clearly made. If we are ever to make those connections, we must go back at least a few years, though an even longer view must eventually be taken.

First, as an idea, the $\mathrm{CDC}$ arose in reaction to the successes and failures of the civil rights movement. The significance of this movement as part of broad social trends in America has not yet been adequately described in the near-revolutionary terms it deserves. ${ }^{3}$ The successes of the movement in bringing about improvements in the legal status and privileges of blacks only put into high relief the basic economic deprivation that this group suffered. The main beneficiaries of the successes were and are in many respects the middle-class blacks who can take advantage of newly opened opportunities. The vast majority of the black people, despite all the civil rights victories, still face an economic future that raises basic questions about the means and processes of an economic system that has cost the blacks so much. Thus, various civil rights activists of the last decade began again to raise the idea of a different economic system, using the principle of a group rising in economic status as a group, as contrasted with the conventional conception of individual improvement by individual effort. In the early I960's, this idea was espoused in the political demands that finally brought forth President Johnson's poverty program. ${ }^{4}$ Later, a more sophisticated and precise expression arose in the form of the CDC as the instrument of what government officials began to call "community capitalism," but which was, in fact, a movement for neighborhood-controlled and neighborhood-owned economic enterprise.

Second, as an institution, the CDC evolved as a reaction to the promise, the accomplishments, and the disappointments of the central institution of the antipoverty program, the community action agency (CAA). The promise of the CAA was that it would be an instrument that would represent the poor (especially the black poor) and be their advocate in eliciting resources for them from the more affluent environment. The reality was a disappointment. It was clear that the CAA did not swiftly or surely elicit enough resources for the poor. But that might have been tolerated as part of a long-term struggle if the CAA had really offered the poor a social instrument of their own. The worst disappointment was that the CAA did not represent the poor; it really represented the whole local community, the rich and middle class as well as the poor. This was in part a result of the composition of the CAA boards. One-third of the board members were appointed by local government; one-third came from social and welfare agencies; and only the remaining third were selected by the poor themselves.

Insofar as a majority of CAA board members did not come from the ranks of the

\footnotetext{
${ }^{3}$ Preliminary insights are presented in the examination of the relationships between the blacks, the civil rights movement, and the youth culture in H. PERRY, THE HuMaN BE-IN (1970).

'See S. Levitan, The Design of a Federad Anttpoverty Strategy (1967).
} 
poor themselves, the CAA certainly was not an instrument controlled by poverty area residents even though its aims were geared to those areas and those residents. Therefore, the CAA became a forum in which many interests of the whole community were compromised before outside demands were made by the agency in the name of the poor. The representatives of local government, charities, businesses, foundations, and social welfare agencies who sat upon the CAA boards had first to fight out among themselves the different demands that they brought from their varying allegiances before they could do battle in the name of the poor. Naturally, the demands defined by this compromising process often differed from what the poor would have expressed for themselves.

However, among the accomplishments of this institutional instrument was one that offered the springboard for a new approach. The CAA personnel budgets subsidized many poor neighborhood residents in low-level jobs that either left them free or actually enjoined them to organize their neighbors to make more effective demands, within and without the poverty program. A whole new cadre of leaders developed as a result. Included were some people who might never have had a chance otherwise to escape from the daily grind of more meaningless occupations, people who had not previously had the economic freedom to participate as leaders in the civil rights movement. Free to think in basic political terms and to organize neighbors on those terms (usually without respect to conventional partisan groupings), these people became a new resource to their neighborhoods.

In this sense the CAA's were successful; by investing in the development of human leadership capital (however unintentionally), they produced a new resource for the poor neighborhoods-a pool of individuals with the social vocabulary of experiences and skills necessary for moving through the system to secure opportunity for their neighborhood. These people together with others who had already provided civil rights leadership, and who were also occasionally subsidized for a time by the poverty programs, made up a critical mass of articulate and insightful spokesmen on the local level. They were able to support each other when it finally became evident that the old goals and the compromising instruments of the CAA no longer fit the rising expectations of an activated neighborhood.

The conventional CAA did not fulfill enough of what the poor came to see as their needs, and out of the ferment created by the rights movement and the poverty programs, a whole set of new or rediscovered activities arose, including the collective civil disorder or riot. Among the many other social creations of the black poor in this period were organizations that exemplified three principles: (I) the instrument of action must be controlled by the neighborhood and the neighborhood alone; (2) neighborhood political power requires economic power embodied in control of existing economic institutions and the creation of new ones; and (3) the improvement of the political, social, and economic status of the neighborhood requires a coordination of efforts in all three sectors and a coalition of all those active in the neighborhood. 
The CDC was only one of a wide variety of models based on these principles, and it too varied in form. In its most powerful form, the CDC is intended to include a broad representation of the spectrum of leadership, ranks, and class in the neighborhood, and thus to act as a unified spokesman. An example of this potential scope is the Hough Area Development Corporation of Cleveland, Ohio, a CDC which included in its membership virtually every influential leader in the Hough neighborhood. Another example is Fighton, an economic development corporation in Rochester, New York, that was organized as a subsidiary of a federation of all local civil rights groups and interests.

In black communities, the $\mathrm{CDC}$ has sought, by business and other economic development activities, to strengthen black power with economic muscle. It is not designed for the limited purpose of providing services for the neighborhood, as the CAA usually is. It also has sought a coordination of plans for the neighborhood by persons exclusively responsible to the neighborhood and representative of it-unlike Model Cities programs, which are run by the city mayor or his delegate. In these ways a CDC is designed to avoid the political and functional limits of the CAA (and Model Cities units) and thus to broaden the scope of the civil rights movement.

The structure of this new institution has varied considerably, since in each location it was a local response. There was no model to be copied. The original innovations of the Zion Investment Associates in Philadelphia, the Fighton Corporation in Rochester, the Hough Area Development Corporation in Cleveland, and so on, were in 1967 truly indigenous inventions. ${ }^{5}$

The degree to which the CDC's are truly responsive to their constituency also varies from case to case, but not in relation to such structural features as direct election of leaders by residents at large. This is not to say that both questions of structure and of responsiveness will not jeopardize the future of the CDC's in general or in some specific cases. The point is that the source of their initial energy was their credibly representing their constituencies.

Today, in recognition of the fundamental flexibility of the CDC, many groups other than blacks have established their own versions of this institution. The underlying conception is expressed in still other structural forms, some of which had existed before-such as production cooperatives of the rural poor. What underlies them all, however, is adherence to the principle of community-based economic development-economic development activities controlled by the heretofore underrepresented, under-privileged, and under-developed communities or neighborhoods and their residents. That is perhaps the only common characteristic that describes the members of the National Congress for Community Economic Development-an association recently founded for mutual support by leaders of some of the new

\footnotetext{
${ }^{s}$ Actually the Reverend Leon Sullivan's ZTA did not become open to any but Zion Baptist Church members uncil 1968, but its roots in the so-called "I0-36 plan" (ten dollars a month from each member for thirty-six months) date back to 1962 .
} 
CDC's. Mexican-Americans, Indians, Puerto Ricans, Appalachian whites, and urban ethnic whites, as well as blacks, are among those now who are working with a CDC tool for economic development. The CDC idea has also been under consideration recently in at least one upper-middle-class suburban attempt to gain local hegemony -in the Isla Vista neighborhood of Santa Barbara, California.

The impetus for new structures comes from a demand in local neighborhoods for a return of a measure of control over their immediate environment. This neighborhood trend in depressed areas coincides with the upsurge of concern in middle-class communities with a different facet of the issue of self-determination-that which is exemplified by increased feelings of personal alienation from social, political, and economic institutions. In middle-class communities the problem is defined in individualistic terms rather than group or neighborhood terms. For example, with the middle-class citizens, especially younger ones, the solution to alienation is through a search for different styles of personal relatedness-greater intimacy in communal living arrangements, encounter groups, and the like. With the low-income minorities, on the other hand, the solution to alienation is to get together for group advancement through joint economic endeavors. Thus, the CDC is only one institutional precipitate from only one social stratum responding to increased demands for autonomy, self-determination, or participatory democracy in a mass society. Yet because it is in fact a part of a broader social trend affecting other strata, it is especially important. For one thing, it is possible that the $C D C$ as an institutional form will attract middle-class citizens who seek economic decentralization as a solution to alienation in the economic sphere.

II

\section{Decentralization of Power}

The generalized application of both the institution and the idea of the CDC from low-income blacks to other groups has implications for national domestic policy and, hence, for programs based on that policy. Governmental policies favoring decentralization are the most obvious concomitants of the present local trends. Revenue-sharing or other decentralization proposals founder, however, on the problem of finding, creating, and defending institutions which can carry out the activities to be decentralized. For example, decentralizing federal manpower programs to the state employment services surely means miring these programs in distracting politics, institutionalized racism, and inefficient bureaucracy. Or to take another example, a revenue-sharing plan that will leave it up to a city or state to decide whether low-income areas or more influential higher-income areas are to benefit does not inspire confidence in the future of urgently needed urban and rural development.

Whatever decentralization eventually emanates from Washington will involve usually unresponsive state, county, and municipal entities, even when the rhetoric of that decentralization calls for broad citizen control over the new transfers of 
authority. Yet, depending upon local political alignments, the CDC could become a final repository of that authority for the CDC's neighborhood. It is this potential which gives the $\mathrm{CDC}$ relevance for national policies of decentralization, including revenue-sharing. Where the CDC in fact lives up to its ambitious aim, it will be a citizen advocacy center for a neighborhood or region and can coordinate and focus the special demands of that area. And because of its administrative experience in other activities, it will also be a natural candidate for delegation of municipal service functions.

The organizational flexibility of the CDC will enable it to move into different fields through the use of semi-independent sub-organizations. It could, for example, take over activities such as low-income housing construction, refuse removal, street maintenance, and institutional supplies and services for public schools and hospitals on delegation or contract from local entities. Insofar as the CDC represents no single entrepreneur or group of persons who will privately benefit, but rather an entire geographical neighborhood that will publicly benefit, the delegation of such functions is politically defensible. The degree of the CDC's responsiveness to and control by the citizens in its area will be the key to its salience as the incontestable local instrument for local affairs. The presence of local responsiveness and control makes it politically necessary for outsiders to deal with the CDC. Of course, this assumes both that the area is sufficiently organized to have a real identity vis-à-vis the rest of the city or county and that its constituents can be mobilized on election day. An effective $C D C$ will meet these assumptions.

Middle-class areas ordinarily do not have such identities, probably because the individual resident finds its easier, without high levels of local organization, to direct municipal attention to a neighborhood problem. For example, the pot-hole in the street just beyond a middle-class driveway gets fixed more quickly as the result of a telephone call than when the call is about a repair need in a low-income neighborhood. When the central administrations become unresponsive, however, it seems likely that even middle-class neighborhoods will organize an instrument like a CDC to accomplish local goals. That seems the lesson of Isla Vista which experienced a police riot that ordinarily occurs only in a slum. Indeed, it is precisely the fact that a CDC arises to meet local needs that makes the CDC much more likely to fit those needs than some externally induced subdivision of the city, county, or state.

In short, it would seem that a rather natural political and social evolution could occur, mainly out of local needs, to give meaning to decentralization as a national policy. True decentralization cannot occur unless the recognition of what needs to be done happens at the lowest level of citizen organization-the neighborhood. This of course has been argued by many observers, most recently by Milton Kotler. ${ }^{\circ}$ The $\mathrm{CDC}$ is the embodiment of much of what Kotler foresaw as the necessary beginning to the return of local affairs to local control.

\footnotetext{
${ }^{\circ}$ M. KotLer, Neighborhood Government (I969).
} 


\section{III}

\section{The Community Development Corporation in Rural Areas}

The CDC has evolved in the urban areas, gaining much of its potential from the fact that its members live in close proximity to each other and, therefore, are mutually accessible for communication and mobilization on common problems. Quite a different situation, of course, characterizes any attempt by rural people to join in common action. The dispersal of population and, often, a great heterogeneity of class, status, and perspective pose more significant barriers to community organization. Nevertheless, the economic situation of the rural poor and near-poor offers a strong common bond for one major CDC activity-the creation of new employment and income opportunities in tune with local needs.

The need for employment and other income opportunities in rural areas is very different from that which exists in the urban neighborhood. In the cities, there are unfilled job opportunities even in the midst of recession, albeit to a considerably lesser degree. Housing patterns, inconvenient transportation, and a variety of artificila barriers including discrimination, tend to prevent the filling of those jobs from among the ranks of the unemployed or underemployed. But in the depressed rural areas, often there are no jobs; and often there is no particular likelihood that jobs will open up even if great prosperity covers the rest of the nation.

It is true that federal programs have been devised for these forgotten areas. But efforts such as the Appalachian Regional Commission and the Economic Development Administration have not produced any convincing evidence of major success. These programs apparently continue because more promising alternatives have not appeared.

The recalcitrance of the rural problem has led some to suggest that it be ignored, that "uneconomic" areas be allowed to die or simply remain stagnant. In this unencouraging context, the arousal of hope and the harnessing of joint energies that only a local institution like a CDC can achieve may be a new tool. CDC's could not or would not supplant any of the other rural development activities. The point is that here, too, decentralization to locally evolved institutions may play an important supplemental part in any attempt to devise a broad strategy for rural development. ${ }^{7}$ Certainly, the usual policy based upon giving local incentives to outside companies to move their plants to rural locations cannot solve the rural problem. First, what is one area's gain is another's loss. Second, we have witnessed how little effect county booster groups, even with state help, have in such efforts. And finally, there is in-

\footnotetext{
${ }^{7}$ A particularly instructive comparison is the miserable record of a Department of Agriculture project in economic development in southeastern Kentucky, as juxtaposed with the moderate success of a coincidental project in an equally distressed area of North Carolina. In the first case, interference by the federal agency stymied any meaningful activity and encouraged a destructive atmosphere of inter-county competition; in the latter project a more representative group of the counties concerned effectively capitalized on the opportunities for economic development that were open to them. See I \& II Westinghouse Learning Corporation, An Evaluation of Fiscal Year ig68, Special Impact Programs ( 1969$)$.
} 
creasing evidence that even when an industry is brought in from the outside, the costs to the community may be more than the benefits, under existing incentive programs. For instance, unemployment may be little affected if the plants bring their own employees. Perhaps, on the contrary, new possibilities for local control and changethat is, for self-determination-through a different institutional tool can mobilize a local rural community to a different pattern of combining the local and the necessary outside resources.

Rural cooperatives, and in recent years other $\mathrm{CDC}$-like organizations, ${ }^{8}$ are able to arouse new activity because the institutional limitations of conventional county government can be transcended. New human resources can be tapped from constituencies that have been ignored in the past. The most obvious examples are the minorities in the South and Southwest. As illustrated in the case of HELP in Northern New Mexico and ECCO in Hancock County, Georgia, new economic energy can be released with benefit to an entire rural area.

The special advantages of a new institution responsive to a previously underutilized constituency is threefold at least. First, new knowledge is brought to bear on local problems, so that the creation or attraction of new industry or business can be adapted more specifically to local needs for jobs in terms of local skills available. For example, those who know the job needs of the community will not seek an industry which will bring its own employees. Second, the multi-purpose design of the CDC, together with emphasis upon community ownership, brings to light many considerations in local business development that are usually ignored. The CDC can assess trade-offs between community needs and profit level in a way that organizations with more restricted ownership and single-minded profit considerations cannot. Third, the CDC as a new instrument can do things that long-established institutions cannot. It may be argued that the under-utilized constituencies can make their influence felt through extant local government institutions by the simple process of registering and voting. It is true that electorial influence is essential in any case, but it is also well recognized that any major redirection of the whole set of established local government bureaucracies is impossible even with the election of sympathetic executives. It is, then, for this reason also that the CDC or its analog can be especially effective in stagnant rural communities.

The common feature of the energy released by the CDC in the urban areas and by the CDC in a rural area is the new sense of community self-determination. In the urban areas, this has primarily reflected the energy potential of the racial identity movement. The same potential is possible in racially or ethnically distinct rural areas of Chicanos or blacks. Yet, the necessary sense of new community possibilities can occur even in mixed or white rural areas because rural people can

\footnotetext{
${ }^{8}$ As has been made plain, the CDC is significant as a multi-purpose development institution. Insofar as cooperatives serve only to reduce their members' production, marketing, or purchasing costs, they are not capable of the same systematic development of their area. Many co-ops, however, do engage in multiple activities, such as community organization on local issues, initiating credit unions, and so on. In these instances they then perform the same broad community function as a CDC might.
} 
more clearly sense the handicaps of their economic environment: It is easier for them. to recognize that whatever is wrong is not an individual matter, but rather a community or area condition of lack of opportunity.

\section{IV}

\section{Recommendations for Specific Actions}

There are certain specific actions which can be taken on a national level by congressional or executive initiative to insure that new and existing domestic programs benefit from the CDC phenomenon. Basically, the policy position must be one which is permissive rather than prescriptive.

Presently, many federal laws are framed or applied in such a way as to exclude CDC's from participation in benefits available to other business or community groups. At a minimum, we need to insure that federal law does not stand in the way of use of this new social institution. But mere neutral openness to the CDC's will not always be enough; at some later date, there will have to be massive encouragement through federal grant and loan funds. ${ }^{9}$ However, at this point, some fairly limited federal actions can create a generative climate for $\mathrm{CDC}$ growth, and that alone can be extremely useful at the current stage of CDC development. Administrative interpretations and existing legislation can be modestly changed now so as to permit the utilization of a CDC whenever a CDC is prepared to carry out a project within a current federal program. Similar opportunities, of course, must be provided by state and local law and regulation.

The most important areas of national programming that are relevant here are business and agricultural assistance, urban renewal, housing, and what is being called the "new communities" approach. Other potentially relevant federal programs -for example, in environmental protection and conservation-ought to be scrutinized to make sure that the instrumentalities for carrying them out are so defined as to permit the use of CDC's; but the former programs are so central that I shall concentrate on them in illustrating the constraints placed on community-based development groups.

First, the economic development assistance provided by EDA goes only to depressed areas approved by EDA in accordance with administrative regulations which require a submission by a local governmental unit, or delegated body, of a comprehensive development plan-the Overall Economic Development Plan (OEDP). The

\footnotetext{
The experience of similar development groups abroad (such as the kibbutzim in Palestine) established the need for considerable outside assistance, both in the initiation stages and in continuing development. Presumably the same will be true in any American models, with the federal government being the major source of outside assistance. Among the mechanisms that will eventually be necessary is some sort of national development bank. Various congressional proposals have been advanced on this instrument over the last few years. However, a bank is only one part of the necessary system, and an integration of many elements will be necessary. The proposed Community Self-Determination Act (now known as the Community Corporation Act, proposed in a Senate Labor Committee print) is one form of a systematic federal program, and the current Special Impact program of OEO is a microcosm test of what some of that progran might look like.
} 
approval process has been administered so as to militate against the channeling of assistance to certain low-income areas (called Special Impact areas) which are now being developed by CDC's. Legislative provision in the Economic Opportunity Act encourages the designation of these areas by EDA as eligible for assistance. Yet, they have not received that assistance, mainly because the CDC's working in them are not given appropriate recognition by EDA.

For example, the author was present during a discussion between EDA officials and a group of OEO CDC directors in which the EDA position was made explicit: the Special Impact areas would not receive assistance despite the legislated mandate. Earlier, EDA designation of the eligibility of these areas for assistance had been denied on the technicality that an approved OEDP must precede EDA designation. The CDC directors were told, however, that EDA would not approve any plans or, if approved, the plans would not lead to assistance. The reasons for this remain unclear.

More recently, EDA has indicated that it will provide that assistance in one or two cases on a "demonstration" basis. A recent legislative proposal by Senators Kennedy and Javits to strengthen the claim of the OEO CDC's to EDA assistance may have been a factor in prompting this change. ${ }^{10}$ It was formulated in part as a result of the history of EDA's denial of assistance to the Special Impact areas. Whether the new provision would be effective despite an apparently unsympathetic agency is still problematic. The point here is, however, that the record on EDA assistance is only one illustration of the problems that arise if the use of the CDC movement in national policy is desired.

Second, the creation and expansion by CDC's of businesses in their localities is hampered by regulations which exclude nonprofit corporations and cooperatives from benefits administered by the Small Business Administration (SBA). For example, SBA regulations specifically deny section 8(a) assistance to nonprofit CDC's or their instruments. ${ }^{11}$ The 8 (a) program is the potentially powerful resource of government contracts which may be allocated to smaller companies, in the so-called "set-aside program" of federal procurement that would otherwise go to major corporations. ${ }^{12}$ Since CDC's are in most cases nonprofit, this means that a major economic development resource is denied them. Even in those instances in which they are in a for-profit form, CDC's may be linked to a nonprofit corporation in such a way as to still be excluded from the small business assistance. Yet, the goal of much CDC activity is, of course, the same as that of the SBA, stimulation of business activity. Since the profits of many CDC-sponsored business ventures are used for the benefit of a larger group, SBA funds channeled through a CDC would seemingly have a greater total impact than those directed to small privately-owned concerns.

\footnotetext{
${ }^{10}$ S. 2007 , $92 \mathrm{~d}$ Cong., Ist Sess. (I97I). The measure has been incorporated as a part of title VII in the Amendments to the Economic Opportunity Act of 1964 , the new (I97r) OEO authorization bill that at this writing has gone to the President for action.

11 I3 C.F.R. \$ r24.8-I (Supp. I97I).

${ }^{12}$ Small Business Act, I5 U.S.C. $\$ 637$ (1970).
} 
Third, although inner-city revitalization is the special goal of the majority of CDC's, they are not given reasonable access to the resources that HUD is devoting to this goal. For example, Model Cities regulations prevent the designation of citizen participation units as the arm for economic development. ${ }^{13}$ This should be changed. The needed change would not mean that HUD should require the local mayor to designate citizen-controlled CDC's for administration of development programs. That may be politically impossible for the present. However, HUD should not, as it has in the past, administer the program so as to prevent that designation even when the mayor and the local groups prefer it.

An illustration of the effect of the present limitation is the two-year struggle between HUD and the local Model Cities group in Boston. Although HUD prevailed, its victory was pyrrhic. Economic development now is divided between competing units including the city's community development administration, a CDC created by the model neighborhood board, and citizen groups that have resisted capitulation to programs directed from outside the community. ${ }^{14}$ The result of course is duplication and waste of very scarce resources in ideas and people, as well as funds.

Similar federal agency regulations tend to inhibit the energies of local development groups in the field of housing. For example, nonprofit sponsors of low-income housing, such as CDC's, usually have difficulty getting the necessary seed money to start a project. Although FHA construction loans will retroactively cover the preconstruction investment, the loans cannot be awarded until the preliminary work is done. The Housing and Urban Development Act of Ig68 provides for preconstruction loans, ${ }^{15}$ but the amount authorized is small and would support a total national housing investment of no more than $\$ 75$ million-a pitifully insignificant amount. A minor modification in the legal structure in favor of CDC's could permit them to secure combined preconstruction and construction loans, rather than rely upon the inadequate preconstruction appropriations of the $\mathrm{x}_{968}$ Act.

A final example of the limitations of the current assistance structure is the "new communities" program of HUD, which is designed to insure the orderly increase of sites for new towns. As currently framed, the program requires large amounts of private capital, which of course are ventured only on the prospect of high profits. No CDC is likely to have the necessary capital in its own investment fund, and if it wished to undertake a new town project, it would have to enter into the kind of arrangements for private capital that would rule out the community control approach

\footnotetext{
${ }^{13}$ See Policy Statement on Economic Development for Model Cities Programs, CDA Letter Ioc, MC 3135.I Supp. 2 (Nov. 2970). This regulation does provide that the economic development corporation must be "broadly representative of the community within the Model Cities target area," as well as include people from the "broader city community." However, local city politics being what they are, the governance of this board is securely in the hands of a mayor, if he wants it to be-and of course he usually would.

14 For details of the HUD restrictions, see M. Dean, Boston Model City and the Community Development Corporation, I968 (unpublished course paper, Harvard Business School).

${ }^{16}$ I2 U.S.C. $\$$ I $701 X(a)$ (I970).
} 
that marks CDC ventures. Thus, probably the most exciting new town project in the country, a 5000-acre tract known as Featherfield Farm developed by a community group in southwest Georgia, has struggled against impending disaster for three years without even the necessary seed money to plan properly because of the inability of community-controlled development projects to attract capital comparable to that available to large private developers. Their tenuous hold on the $\$ \mathrm{r}$ million property is a major success story in itself; whether they will in the end manage to attract church and foundation money holds the key to that new town to be built by a CDC. Federal funds are virtually denied them. ${ }^{16}$

\section{ConcLusion}

None of these administrative and legislative restrictions are necessary for proper federal control over the use of federal funds. They tend to frustrate the approach to local development that CDC's exemplify, simply because the task tackled by the CDC is so overwhelming. CDC's appear to be an energetic innovation with high potential for local revitalization programs. They could become the instrument for a renascence of our most depressed areas, and national programs, laws, and policies must be reviewed carefully to remove obstacles to this new democratic development.

\footnotetext{
${ }^{10}$ Cf. The Twentieth Century Fund, New Towns: Laboratories por Democracy (x97r). For a description of the Featherfield Farm project, see Gottschalk \& Swann, Planning a Rural New Town in Southwest Georgia, I ARETEk 3 (1970) (journal of the Graduate School of Social Work, University of South Carolina).
} 